\title{
The Impact of Internet Referral Services on a Supply Chain
}

\author{
Anindya Ghose \\ Stern School of Business, New York University, 40 West Fourth Street, New York, New York 10012, \\ aghose@stern.nyu.edu \\ Tridas Mukhopadhyay \\ Tepper School of Business, Carnegie Mellon University, 5000 Forbes Avenue, Pittsburgh, Pennsylvania 15213, \\ tridas@andrew.cmu.edu \\ Uday Rajan \\ Ross School of Business, University of Michigan, 701 Tappan Street, Ann Arbor, Michigan 48109, \\ urajan@umich.edu
}

\begin{abstract}
Tn many industries, Internet referral services, hosted either by independent third-party infomediaries or by 1 manufacturers, serve as digitally enabled lead generators in electronic markets, directing consumer traffic to downstream retailers in a distribution network. This reshapes the extended enterprise from the traditional network of upstream manufacturers and downstream retailers to include midstream third-party and manufacturerowned referral services in the supply chain. We model competition between retailers in a supply chain with such digitally enabled institutions and consider their impact on the optimal contracts among the manufacturer, referral intermediary, and the retailers. Offline, retailers face a higher customer discovery cost. In return, they can engage in price discrimination based on consumer valuations. Online, they save on the discovery costs but lose the ability to identify consumer valuations. This critical trade-off drives firms' equilibrium strategies. We derive the optimal contracts for different entities in the supply chain and highlight how these contracts change with the entry of independent and manufacturer-owned referral services. The establishment of a referral service is a strategic decision by the manufacturer. It leads to diversion of supply chain profit from a third-party infomediary to the manufacturer. Further, it enables the manufacturer to respond to an infomediary, by giving itself greater flexibility in setting the unit wholesale fee to the profit-maximizing level. Both third-party and manufacturer-sponsored referral services play a critical role in enabling retailers to discriminate across consumers' different valuations. Retailers use online referral services to screen out low-valuation consumers and sell only to high-valuation consumers in the online channel. Our model thus endogenously derives a correlation between consumer valuation and online purchase behavior. Finally, we show that under some circumstances, it is too costly for the manufacturer to eliminate the referral infomediary.
\end{abstract}

Key words: internet referral services; electronic markets; price dispersion; franchise fees; discovery costs; electronic intermediary; digital supply chain

History: M. S. Krishnan, Senior Editor. This paper was received on August 13, 2005, and was with the authors 11 months for 3 revisions.

\section{Introduction}

Information technology plays a strategic role in the digital supply chain of an extended enterprise by changing the nature of the relationships among a broad array of partners such as upstream manufacturers, midstream intermediaries, and downstream retailers. In particular, the past few years have witnessed the emergence of a number of online third-party intermediaries whose basic objective is to provide consumers with information about prices and products. These referral infomediaries, as they are often called, offer consumers the opportunity to get price quotes and invoice prices as well as product reviews and specifications from enrolled brick-and-mortar retailers. Although a referral infomediary does not directly sell a product, it does shift much of the 
consumer search process from the physical platform of the traditional retailer to the virtual world of the Web. It therefore represents a midstream player in a supply chain between a manufacturer and a dealer or between dealers and consumers.

In response, many manufacturers have established their own online referral services. Consider the auto industry in the United States-an industry with $\$ 500$ billion in revenues. Both infomediaries and manufacturers now offer digitally enabled referral services, which are growing in popularity. Industrywide, $25 \%$ of all new vehicles in 2005 were sold through an online buying service, up from $4.7 \%$ in $2000,{ }^{1}$ and Autobytel generated an estimated $\$ 83$ billion in car sales. ${ }^{2}$ Major original equipment manufacturers (OEMs) like GM and Ford have their own referral services, such as GMBuyPower.com and FordDirect.com. From these sites, consumers can configure a new car, receive the list price, and move to a dealer site for inventory and quotes. Crucially, manufacturers provide referrals to the dealer free of cost, and third-party infomediaries charge referral fees to participating dealers.

In the auto industry, franchise laws prevent a manufacturer from directly selling to consumers. To avoid the natural conflict with retailers that emerges when a firm sells directly to its consumers, firms in other industries are also beginning to use their own referral services to steer consumers to retailers. ${ }^{3}$ Tsay and Agarwal (2004) point out that Hewlett-Packard's (HP) Commerce Center is not an online store per se-it simply gives business customers an easy, point-andclick way to order from an HP reseller. On the other hand, computer manufacturers compete with online third-party infomediaries such as CNET.com in the customer lead-generation business. Referral services are also common in the real estate, funeral services, medical devices, and telecom industries.

In this paper, we look at only the pricing aspect of infomediaries and do not consider their role in

\footnotetext{
${ }^{1}$ http://www.autobytel.com/images/newsletters/march/2.html.

${ }^{2}$ http://www.autobytel.com/content/home/help/pressroom/ pressreleases $/$ index.cfm?id=4\&ArticleID $=138893$

${ }^{3}$ A new channel can create channel conflict because consumers compare prices and options across channels. For example, Forman et al. (2006) show that use of the online channel depends on local offline retail options.
}

providing independent information. The conventional wisdom on Internet referral infomediaries is that they are valuable to consumers because they reduce the search costs of comparing prices in electronic markets and enable consumers to get binding price quotes from retailers. However, the impact of these referral services on manufacturers is less clear. Neither is the impact of competition between manufacturersponsored and infomediary-sponsored referral services on contractual fees and profitability in a digital distribution network clear. A manufacturer's entry into the online referral business has implications for pricing, allocation of supply chain profits, and midstream competition.

We focus on the distribution network of a supply chain consisting of a manufacturer, an infomediary, and two competing retailers. We consider a manufacturer that chooses not to engage in direct sales to consumers, possibly to avoid conflict with retailers, and examine the impact of the entry of a thirdparty referral infomediary on the profitability of the upstream manufacturer and on the overall profits in a digitally enabled supply chain. In the context of an extended enterprise, how does establishing its own referral infomediary enable the manufacturer to redirect profits in the supply chain back to itself? How do the optimal contracts between the various parties and the retailer's optimal pricing strategies change? Finally, we consider the costs and benefits to the manufacturer of eliminating the referral infomediary.

In a related paper, Chen et al. (2002) examine how an infomediary affects market competition between retailers, and contractual arrangements that they should use in selling their services. The research shows that a referral infomediary can serve as a device to enable price discrimination across consumer search segments. We extend their work by also examining the role of manufacturer referral services in enabling the manufacturer to compete against the infomediary. We focus, in particular, on the response of the manufacturer to the presence of an infomediary, the impact of this response on retailer pricing, and the reshaping of contracts in the supply chain to competition between the referral services.

In our model, consumers are heterogeneous both in their valuations and in search behavior, so price dispersion exists in equilibrium, as in Varian (1980) and 
Narasimhan (1988). In the offline channel, consumers physically walk into stores, and retailers determine willingness to pay via a costly interaction. This enables them to discriminate offline between highand low-valuation consumers. However, on line they lose this ability to identify consumer valuations. In the auto industry, for example, purchases are infrequent, with significant time gaps. In such a setting, it is reasonable to think of consumer preferences changing from one purchase to the next, so that valuation information on consumers buying the product on line is unavailable. Thus, we model a critical trade-off retailers face between lower online customer discovery costs versus greater consumer information offline.

The overriding theme of this paper is that retailers can use referral infomediaries, whether third party or manufacturer sponsored, as screening devices to identify high-valuation consumers. This enables retailers to extract greater revenues from consumers but is potentially mitigated by increased competition between retailers. Any increase in retailers' gross profit is, in turn, passed up the supply chain to either the third-party infomediary or the manufacturer.

Our paper makes several contributions. First, we find that the establishment of manufacturer referral services, despite no direct sales by the manufacturer to consumers, leads to a diversion of supply chain profits away from a third-party infomediary and toward the manufacturer. As a result, the manufacturer's profit can increase even when total profit in the supply chain is reduced.

Second, we find that online referral services are used by retailers as a device to enable price discrimination based on consumer valuations. Despite assuming no ex ante relationship between offline and online search behavior and consumer valuations, we find endogenously that only high-valuation consumers make online purchases. This mitigates the information loss inherent in online purchase services for consumer durables. On line, retailers cannot directly infer consumer valuations, whereas valuation information is more readily available offline.

Third, despite the potential to unravel the competing referral infomediary, the manufacturer is better off leaving the infomediary in business if the proportion of offline consumers is sufficiently high. To eliminate the infomediary, the manufacturer must increase the wholesale price, which could shut out a large segment of the consumer market, leading to lower sales and lower profit for the manufacturer.

Fourth, the establishment of a referral service by the manufacturer gives it greater flexibility in responding to an infomediary by setting a high wholesale price. This additional flexibility depends critically on heterogeneity among consumers. By charging a higher wholesale price the upstream manufacturer alleviates price competition among the downstream players, leading to higher gross profits for each retailer.

Finally, average online prices offered by retailers to users of the manufacturer's referral service are higher than infomediary referral prices. This is similar to a manufacturer's suggested retail price, which is the highest possible price consumers are expected to pay under normal market conditions. Thus, this result also reconciles well with practice.

Our paper is related to various strands of the literature on Internet-enabled supply chains. Much of this work has focused on procurement and suppliers. For example, Kleindorfer and $\mathrm{Wu}$ (2003) consider a dynamic model with spot and long-term contracting between suppliers and buyers in capital-intensive industries, and Subramani (2004) considers how suppliers can both create and retain value via the use of information technology. In contrast, our focus is on spot contracts in distribution, rather than procurement, and on how the manufacturer and infomediary can use these to generate and retain value.

In our model, digitization facilitates competition between the manufacturer and the infomediaries through their referral services, leading to a reshaping of the extended enterprise. Specifically, digitization is a vehicle to allow price discrimination across consumers with different search behaviors and to increase profits in the supply chain. By using its own referral site, the manufacturer can capture some of this greater profit for itself, rather than allow it to be skimmed off by the infomediary. This would not have been possible in the traditional offline world: For infrequently purchased, high-priced goods, there may not be an effective offline mechanism to engage in price discrimination. Thus, digitization adds value beyond what can be captured in an offline world.

On the face of it, online availability of prices would seem to enhance market transparency. In a businessto-business context, Zhu (2004) shows that increased 
transparency adversely affects firms' incentives to join an exchange. Granados et al. (2006) consider transparency as a strategic choice for a monopolist selling to consumers. Baye and Morgan (2001) show, in a model in which gatekeepers charge fees to firms for advertising their prices, that price dispersion can persist on the Internet. In our model, some proportion of consumers switch on line, and referral services serve as a mechanism to discriminate across consumers with different valuations. Viswanathan et al. (2007) find that consumers who search for prices online obtain lower prices for automobiles than those who do not search online.

Digital supply networks are characterized by electronic interactions between different tiers of a value chain (Straub et al. 2004). Early work on net-enabled organizations and the concept of the extended enterprise focused on the role of information sharing in facilitating cooperation and collaboration in the supply chain among suppliers, manufacturers, and retailers (Choudhury et al. 1999, and Lin et al. 2000). The entry of online infomediaries has changed the shape of the extended enterprise by, in addition, bringing in an element of competition into the supply chain.

Online competition between sellers is considered by Bandyopadhyay et al. (2005) and in a supply chain context by Ghose et al. (2005). More broadly, our paper adds to a rich literature on electronic data interfaces (EDI). Competing approaches to measuring EDI usage are evaluated by Massetti and Zmud (1996), while the business value of EDI technology has been studied by Lee et al. (1999), Chwelos et al. (2001), and Mukhopadhyay and Kekre (2002).

The rest of this paper is organized as follows. Section 2 presents the basic model. Section 3 examines a benchmark case with no referral services, and $\S 4$ analyzes the effect of the infomediary on retail competition. In $\S \S 5$ and 6 , we examine the impact of manufacturer referral services on equilibrium strategies and policies. We provide numerical corroboration of our results in $\S 7$. Section 8 discusses some extensions, and we conclude with some business implications in $\$ 9$. All proofs are available in the online appendix. ${ }^{4}$

\footnotetext{
${ }^{4}$ An online supplement to this paper is available on the Information Systems Research website (http://isr.pubs.informs.org/ ecompanion.html).
}

\section{Model}

Consider a piece of merchandise with the following features: Consumer purchases are relatively infrequent, and the price is high relative to consumers' income. In such a setting, it is reasonable to expect that relatively little information about consumer willingness to pay may be available from online purchase histories. Conversely, at an offline retail store, there is often a negotiation over price, and in the process a salesperson may be able to form a better estimate of a consumer's willingness to pay. Many consumer durables fit this description; examples include cars, household electronic appliances, and real estate. Throughout the paper, we use the automobile industry to illustrate our model and results.

\subsection{Supply Chain}

We examine the retail end of a supply chain with a single manufacturer and two competing retailers, $D_{1}$ and $D_{2}$. The manufacturer charges each retailer a franchise fee, $F$, and a wholesale price, $W$, for each unit of merchandise. We analyze the distribution end of the supply chain under four scenarios: (i) no referral services exist, (a benchmark case), (ii) there is a referral infomediary, (iii) both a referral infomediary and manufacturer referral services exist, and (iv) the manufacturer eliminates the referral infomediary. Referral services are all on line, so in scenarios (ii), (iii), and (iv), the retailers make some online sales in addition to sales offline. All sales are off line in scenario (i). Without loss of generality, production costs are normalized to zero.

Each consumer who visits a retailer off line imposes an incremental price discovery cost, $\delta$. This incremental cost includes items such as the cost of renting real estate for a physical showroom, maintaining a sales staff, and having display models for consumers to test drive, as well as the opportunity cost of time spent in providing product information, negotiation, and completing paperwork. Our results depend only on the difference between offline and online discovery costs, so the online cost is normalized to zero.

With respect to the auto industry, Scott-Morton et al. (2001) show that the average cost to a specific dealer of an offline sale is $\$ 635$ higher than the cost of a sale via Autobytel. Along the same lines, Ratchford et al. (2003, p. 206) show that the Internet has led to a 
"considerable reduction in consumer time spent with dealer/manufacturer sources, most of which is time spent at the dealership requiring the presence of a salesperson." Dealers that handle a higher volume of consumers need to employ more salespeople, have a larger showroom, and maintain a larger fleet for test drives. Thus, discovery costs entail a substantial component that varies with customer flow. We model it purely as a marginal cost that depends on the number of consumers who walk in to a retailer, and we discuss the implications of a fixed-cost component after Propositions 3 and 4 below.

The referral infomediary chooses whether to enroll one or both retailers and allows consumers to obtain an online price quote from enrolled retailers. The infomediary charges a retailer a fixed referral fee of $K$ to enroll. For example, infomediaries such as Autobytel. com and Carpoint.com charge dealers an average fixed monthly fee of around $\$ 1,000$, depending on dealer size and sales (Moon 2000).

We focus on the role of the infomediary in providing information about prices to consumers. Of course, infomediaries also provide an important service by allowing consumers to access independent third-party information about the quality or features of a product. In this paper, we restrict attention to referral services that allow consumers to obtain online prices, as opposed to any other information about the product.

\subsection{Consumers}

The market consists of a unit mass of consumers. Consumers are heterogeneous both in terms of their valuation and in their search behavior. A consumer's valuation for the merchandise is either high, $V^{h}$, or low, $V^{l}$, where $V^{h}>V^{l}>0$. The proportion of highvaluation consumers is $\lambda$. Each consumer buys either zero or one unit of the product.

Consumers also differ in their search behavior, based on an implicit notion of search costs. Therefore, different consumers may observe different sets of prices. A consumer with valuation $j$ buys if her net utility is positive; i.e., $V^{j}-P_{\min } \geq 0$, where $P_{\min }$ is the minimum price offered to this consumer.

The focus of our paper is consumer search for the price of a product. In the context of the auto industry, the starting point in our analysis can be those consumers who have already decided on a specific brand and make of car and are now interested in searching for prices for that particular vehicle.

We classify consumers into search segments, based on the prices they observe. We consider three distinct segments: (i) a proportion $\alpha_{u}$ of "uninformed" consumers, who are less informed about different prices and hence obtain a price from just one retailer; (ii) a proportion $\alpha_{p}$ of "partially informed" consumers, who obtain a price from one retailer and the referral infomediary (when it exists); and (iii) a proportion $1-\alpha_{u}-\alpha_{p}$ of "fully informed" consumers, who obtain prices from both retailers as well as the referral infomediary. This is very similar to the consumer framework used in Varian (1980) and Narasimhan (1988).

Our uninformed segment captures both the notion that some consumers engage in limited search because of high opportunity costs of time (see, e.g., Ratchford et al. 2003) and that some consumers are loyal to a given retailer, perhaps because of satisfaction from previous purchases. ${ }^{5}$ Thus, this segment of consumers is "less informed" because the individuals have a lower interest in acquiring information about prices and choose to be aware of the price at one firm only. For convenience, in comparison to other segments, we call them "uninformed."

Informed consumers in our model are akin to switchers who shop around for prices and finally purchase from the retailer charging the lowest price. These consumers are either partially informed (moderate searchers who are interested in observing two prices) or fully informed (extensive searchers who are interested in observing all three prices).

In terms of empirical justification from the auto industry, Cattin and Punj (1983) and Pandraud et al. (2005) demonstrate that a significant proportion of consumers are loyal to a single dealer. Using a data set of auto purchases in Europe, Pandraud et al. (2005) find that $47 \%-79 \%$ of auto buyers visit only one dealer. Klein and Ford (2003) show that 39\% of automobile shoppers search for prices across two or fewer dealers. Thus, there is ample empirical evidence to suggest that some consumers receive only one price, and others receive two or more prices.

\footnotetext{
${ }^{5}$ Numerous other costs have been suggested that prevent consumers from searching for prices, including costs of frustration from, for example, dealing with incompetent salespersons (Downs 1961).
} 
We do not assume any correlation between consumer valuations and search behavior. The empirical evidence on this is mixed. On the one hand, higherincome consumers are more likely to have access to the Internet. However, they also have a high opportunity cost of time and hence may not search as intensively. For example, Klein and Ford (2003) show that there is a significant negative relationship between an auto buyer's income and total time spent in searching for prices. We later show (in \$5) that this sort of a correlation between search and valuation actually emerges endogenously in our model, as a result of the pricing strategies chosen by retailers.

When a consumer approaches a retailer for a price quote, the retailer is unable to distinguish which search segment a consumer belongs to. That is, either off line or on line, a retailer cannot determine the set of prices observed by a particular consumer. However, we assume that off line, the retailer is able to determine the consumer's valuation for the product, whereas one disadvantage of online purchases for the retailers is that they do not obtain information about consumer valuations. For example, ScottMorton et al. (2003, 2006) mention that dealers in offline channels use various cues to infer consumers' willingness to pay; these cues are not easily available online.

We make two assumptions throughout the paper. First, we assume that $\lambda \leq V^{l} / V^{h}$, so that the proportion of high-valuation consumers is not too high. Otherwise, low-valuation consumers may be completely shut out of the market (for example, the manufacturer may find it optimal to set the wholesale price $W$ close to $V^{h}$ ). Second, we assume that the discovery $\operatorname{cost} \delta$ is sufficiently low to permit retailers to earn a nonnegative gross profit in each scenario. Specifically, we require that $\delta \leq\left(V^{l}+\alpha_{u} \lambda\left(V^{h}-V^{l}\right)\right) /$ $\left(2-\alpha_{u}\right)^{6}$

\section{Offline World: No Referral Services Exist}

We now analyze each of the four scenarios mentioned, starting with the case of no referral services. Each scenario is described by a multistage game. We consider

${ }^{6}$ Details behind this expression are provided in the proof of Proposition 3.
Table 1 Prices Observed by Each Consumer Segment when No Referral Service Exists

\begin{tabular}{lccccc}
\hline Types & $\alpha_{u} / 2$ & $\alpha_{u} / 2$ & $\alpha_{p} / 2$ & $\alpha_{p} / 2$ & $1-\alpha_{u}-\alpha_{p}$ \\
\hline HV consumers & $P_{1}\left(V^{h}\right)$ & $P_{2}\left(V^{h}\right)$ & $P_{1}\left(V^{h}\right)$ & $P_{2}\left(V^{h}\right)$ & $P_{1}\left(V^{h}\right), P_{2}\left(V^{h}\right)$ \\
LV consumers & $P_{1}\left(V^{\prime}\right)$ & $P_{2}\left(V^{\prime}\right)$ & $P_{1}\left(V^{\prime}\right)$ & $P_{2}\left(V^{\prime}\right)$ & $P_{1}\left(V^{\prime}\right), P_{2}\left(V^{\prime}\right)$ \\
\hline
\end{tabular}

Note. $\mathrm{HV}=$ high-value; $\mathrm{LV}=$ low-value.

a subgame-perfect equilibrium of the game in each case and therefore analyze the game via backward induction.

When neither the referral infomediary nor the manufacturer referral service exist, the stages in the game are as follows. In Stage 1, the manufacturer sets the franchise fee, $F$, and the optimal wholesale price, $W$, for each retailer. In Stage 2, retailers simultaneously choose retail prices $\left(P_{1}\left(V^{h}\right), P_{1}\left(V^{l}\right)\right)$ and $\left(P_{2}\left(V^{h}\right)\right.$, $\left.P_{2}\left(V^{l}\right)\right)$. In Stage 3, consumers decide which product to buy.

Consider each of the three search segments:

(i) Uninformed consumers, of market size $\alpha_{u}$, observe just one offline price from one retailer. We assume these consumers are equally likely to visit $D_{1}$ and $D_{2}$.

(ii) Partially informed consumers, of size $\alpha_{p}$, behave in exactly the same way as uninformed consumers when there is no infomediary. Hence, these consumers also visit $D_{1}$ and $D_{2}$ with equal probability.

(iii) Fully informed consumers, of size $1-\alpha_{u}-\alpha_{p}$, obtain prices from both retailers.

The prices observed by consumers in different market segments are depicted in Table 1 . In the offline world, the retailers perfectly observe each consumer's valuation. Hence, the prices offered to consumers depend on their valuations. As a result, this basic model reduces to that of Varian (1980). Using similar arguments as in Varian (1980) and Narasimhan (1988), we can show that no pure-strategy equilibrium exists in the subgame that starts at Stage 2. There is, however, a symmetric mixed-strategy equilibrium in which both retailers have equal market shares and offer randomly chosen prices to the consumers. Both dealers adopt the same price distribution for each consumer type, and each retailer has a market share of one-half. ${ }^{7}$

\footnotetext{
${ }^{7}$ The intuition behind this equilibrium is that there exists some
} amount of dispersion in retailer prices across channels and also 
With a slight abuse of terminology, we refer to the profit earned by retailers before they pay the franchise fee $F$ and (where applicable) the referral infomediary fee $K$ as their "gross profit." When there is no referral service, the manufacturer optimally sets the franchise fee $F$ to extract the entire gross profit of the retailers. That is, in our model, all bargaining power rests with the manufacturer. This is not a crucial assumption. The model is robust to either retailers having some bargaining power or retailers having a reservation profit. ${ }^{8}$

The equilibrium in this case is described in the following proposition. The proof of the proposition (and all other results) is in the online appendix. In Appendix A1 at the end of the paper, we provide mathematical details of the pricing strategies, the manufacturer's franchise fee, and manufacturer and channel profits.

Proposition 1. (i) The manufacturer optimally sets the wholesale price equal to the valuation of the low type consumer.

(ii) In equilibrium, each retailer charges a price equal to its valuation to low-type consumers and randomly chooses a price for high-type consumers, such that on average these consumers earn a surplus.

(iii) The manufacturer sets the franchise fee to extract the entire gross profit of the retailers, net of discovery cost.

(iv) The retailers make a zero profit after paying the franchise fee.

(v) Total profit in the supply chain equals the manufacturer's profit and increases as offline discovery cost increases, the proportion of high-value consumers increases,

between retailers within a given channel. This may occur because of intertemporal price discounts through rebates and promotions offered to consumers by different auto dealers at different times. Prior research has also interpreted such equilibrium strategies as sales through the use of coupons or price promotions (Varian 1980).

${ }^{8}$ If retailers have some bargaining power, either the Nash or the Rubinstein bargaining approaches will imply that the gross profit earned by retailers is split between the manufacturer and the retailers in some fashion, say in the proportion $\nu$ for the manufacturer and $(1-\nu) / 2$ to each retailer. When an infomediary is present, it in turn claims a share of the total channel profit. If retailers have a reservation profit $R>0$, each retailer must earn $R$ in equilibrium, reducing the franchise fee by $R$ and the manufacturer's profit by $2 R$. Equilibrium strategies in the retailers' subgame are not affected if $R$ is a fixed quantity. and the proportion of uninformed or partially informed consumers increases.

Note that in our model, it is no longer optimal to set the wholesale price equal to the manufacturer's marginal cost (zero). Setting a wholesale price below $V^{l}$ leads to lower prices on an average, as retailers find themselves in fierce competition. This price reduction decreases profits and thus leads to a reduction in the franchise fee. Conversely, setting a higher wholesale price alleviates the extent of price competition between downstream retailers in the supply chain.

\subsection{Correlated Search}

Note that in the base model, the optimal pricing strategy for high-valuation consumers depends on the size of informed and uninformed segments. Suppose the segments were endogenously determined by the retailers by investing in some advertising or customer acquisition strategies in a previous stage. This would lead to the emergence of correlations between valuations and search behavior. Even if differences in the search behavior of the low-valuation consumers lead to difference in sizes of the segments, the nature of the equilibrium remains unchanged. The lowvaluation consumers will be charged a price equal to their valuations, and the prices for the high-valuation consumers will be randomized. This is because the optimal pricing strategies will only depend on the size of the segments.

\section{Model with Referral Infomediary}

Now, consider the entry of a third-party referral infomediary that allows consumers to obtain prices from the retailers it enrolls. The infomediary has the choice of enrolling either one retailer $\left(D_{2}\right)$ or both $\left(D_{1}\right.$ and $\left.D_{2}\right)$. We first show in this section that the infomediary earns a zero profit if it enrolls both retailers. Next, we show that it earns a positive profit if it enrolls just one retailer. ${ }^{9}$ Further, such a choice also leads to a higher profit in the entire channel.

\footnotetext{
${ }^{9}$ Trivially, the infomediary also has the option of enrolling zero retailers, in which case it again earns a zero profit.
} 
Table 2 Prices Observed by Each Consumer Segment If Infomediary Enrolls Both Retailers

\begin{tabular}{lccccc}
\hline Types & $\alpha_{u} / 2$ & $\alpha_{u} / 2$ & $\alpha_{p} / 2$ & $\alpha_{p} / 2$ & $1-\alpha_{u}-\alpha_{p}$ \\
\hline HV consumers & $P_{1}\left(V^{h}\right)$ & $P_{2}\left(V^{h}\right)$ & $P_{1}^{r}, P_{2}^{r}, P_{1}\left(V^{h}\right)$ & $P_{1}^{r}, P_{2}^{r}, P_{2}\left(V^{h}\right)$ & $P_{1}\left(V^{h}\right), P_{2}\left(V^{h}\right), P_{1}^{r}, P_{2}^{r}$ \\
LV consumers & $P_{1}\left(V^{\prime}\right)$ & $P_{2}\left(V^{\prime}\right)$ & $P_{1}^{r}, P_{2}^{r}, P_{1}\left(V^{\prime}\right)$ & $P_{1}^{r}, P_{2}^{r}, P_{2}\left(V^{\prime}\right)$ & $P_{1}\left(V^{\prime}\right), P_{2}\left(V^{\prime}\right), P_{1}^{r}, P_{2}^{1}$ \\
\hline
\end{tabular}

\subsection{Infomediary Enroll Both Retailers}

First, suppose the infomediary enrolls both retailers. Table 2 depicts the prices observed by each segment. The uninformed segment, which does not use the referral infomediary, sees only one price, as before. Consumers in the partially informed segment see the online referral prices from both the retailers, plus an offline price from one retailer. Those who are fully informed see all four prices (two offline and two online).$^{10}$

There are now four stages to the game. At Stage 1, the manufacturer sets the franchise fee, $F$, and wholesale price, $W$. At Stage 2, the referral infomediary sets a referral fee, $K$, and enrolls both dealers. At Stage 3, retailers simultaneously choose offline and online prices. Each retailer chooses $\left(P_{1}\left(V^{h}\right), P_{1}\left(V^{l}\right)\right)$ for offline consumers and $\left(P_{1}^{r}, P_{2}^{r}\right)$ for online consumers. Note the difference with the model with no infomediary: Offline consumers still obtain a price that depends on their valuation, but online consumers receive a price independent of their valuation. At the last stage, consumers decide which price to accept.

The crucial aspect of the search segmentation is that there is no segment that sees just one referral price but not the other (i.e., just $P_{1}^{r}$ and not $P_{2}^{r}$ or vice versa). The existence of a segment that sees only one referral price is critical to sustain equilibria with strictly positive profits (see, e.g., Varian 1980 or Narasimhan 1988). In the absence of such a segment, the referral prices are set as they would be in Bertrand competition, i.e., to marginal cost $W .{ }^{11}$

Therefore, all consumers in the partially informed and fully informed segments buy at the referral price, $W$, and retailers earn zero profit from such sales.

\footnotetext{
${ }^{10}$ The online referral price is committed to the customers before they come into the physical stores. This prevents the dealer from changing the committed price once he meets with the customer in the offline channel, even though dealers can infer their valuations.

${ }^{11}$ Note that the analysis is unchanged if the entire group of partially informed consumers visits only one retailer, either $D_{1}$ or $D_{2}$.
}

In turn, they choose offline prices to maximize their profit from the uninformed segment by charging $V^{h}$ to high-valuation consumers and $V^{l}$ to low-valuation ones. ${ }^{12}$

Because retailers earn zero profit from infomediaryreferred sales, they can earn exactly the same profit by not enrolling with the infomediary and making no sales in the partially informed and fully informed segments. As a result, the maximal referral fee the infomediary can charge is zero.

Proposition 2. Suppose the infomediary enrolls both retailers. Then it must set the referral fee to zero, so that it makes a zero profit. In equilibrium in the retailers' pricing game, the retailers set the referral prices equal to the wholesale price and set offline prices equal to consumer valuations.

Hence, if it enrolls both retailers, the infomediary earns a zero profit. We show next that it earns a positive profit if it enrolls only one retailer. Hence, in equilibrium, the infomediary strictly prefers to enroll only one retailer.

4.1.1. Correlated Search. Suppose we consider the scenario in which, because of investments made by retailers in a preceding stage, the correlations between search behavior and valuations are endogenously determined. ${ }^{13}$ Because offline search behavior is typically driven by the opportunity cost of time, and the online search behavior is driven by access to the Internet, the high-valuation consumers will search on line and the low-valuation consumers will search off line. Our analysis reveals that in equilibrium, the online referral prices are still set to the wholesale

\footnotetext{
${ }^{12}$ This provides one contrast between our model and that of Chen et al. (2002), who also show that an infomediary will enroll only one dealer. In their model, a positive profit equilibrium with price dispersion obtains even if both dealers are enrolled.

${ }^{13}$ We thank the Senior Editor and an anonymous referee for recommending this analysis.
} 
price, $W$, but the offline prices are set equal to consumer valuations. The table depicting the price search behavior is given in the online appendix (see Table 5).

\subsection{Infomediary Enrolls Only One Retailer}

Suppose the retailer enrolls only $D_{2}$ and enables partially and fully informed consumers to obtain an online price from this retailer. The sequence of the game stays the same as before.

As before, uninformed consumers obtain just one offline price and visit the two retailers in equal proportion. Partially informed consumers obtain an online price from $D_{2}$ and an offline price from $D_{1}{ }^{14}$ Fully informed consumers obtain an offline price from each retailer, as well as an online price from $D_{2}$. The prices observed by consumers in different market segments are depicted in Table 3.

Retailers are now asymmetric in terms of the number of consumers who observe their prices. This model, therefore, builds on Narasimhan (1988), who considers asymmetric firms. Further, $D_{2}$ can now quote more than one price to consumers in the fully informed segment, allowing for price discrimination across segments.

Given that $\lambda \leq V^{l} / V^{h}$, it is not optimal for the manufacturer to charge a wholesale price $W>V^{l}$. At such a price, the low-valuation consumers will be shut out of the market (since retailers will charge a price no lower than $W$ ). Hence, consider the choice of $W$ in the region $\left[0, V^{l}\right]$. The equilibrium here depends on whether the manufacturer chooses a low wholesale price (closer to zero) or a high one (closer to $V^{l}$ ). A low wholesale price leads to low retail prices and a lower profit for the manufacturer.

Therefore, for ease of comparison throughout the paper, we consider the choice among prices sufficiently close to $V^{l}$. In particular, as we show in Lemma 1 in the online appendix, there is a threshold value of $W$ (which we call $\widehat{W}$ ) such that the equilibrium strategies of the dealers for any wholesale price $W \in\left[\widehat{W}, V^{l}\right]$ can be described in terms of $W$. This allows us to determine the optimal wholesale price in this region. Because retailers are asymmetric with respect to market coverage, the equilibrium here

\footnotetext{
${ }^{14}$ Since their online price comes from $D_{2}$, they visit $D_{1}$ for an offline price.
}

Table 3 Prices Observed by Each Consumer Segment when Infomediary Enrolls Only One Retailer

\begin{tabular}{lcccc}
\hline Types & $\alpha_{u} / 2$ & $\alpha_{u} / 2$ & $\alpha_{p}$ & $1-\alpha_{u}-\alpha_{p}$ \\
\hline HV consumers & $P_{1}\left(V^{h}\right)$ & $P_{2}\left(V^{h}\right)$ & $P_{1}\left(V^{h}\right), P_{2}^{r}$ & $P_{1}\left(V^{h}\right), P_{2}\left(V^{h}\right), P_{2}^{r}$ \\
LV consumers & $P_{1}\left(V^{\prime}\right)$ & $P_{2}\left(V^{\prime}\right)$ & $P_{1}\left(V^{\prime}\right), P_{2}^{r}$ & $P_{1}\left(V^{\prime}\right), P_{2}\left(V^{\prime}\right), P_{2}^{r}$ \\
\hline
\end{tabular}

follows the lines of the equilibrium in Narasimhan (1988). As before, no pure strategy equilibrium exists. The details of the equilibrium are contained in Lemma 1 in the online appendix.

Intuitively, the entry of the referral infomediary leads to an increase in competition between the two retailers. Retailer $D_{2}$ uses the infomediary as a pricediscriminating mechanism. Essentially, $D_{2}$ now has two weapons: It uses its online referral price to compete with $D_{1}$ and the offline prices to capture the entire consumer surplus from its captive uninformed segment. The online infomediary referral price, $P_{2}^{r}$, is therefore used to discriminate between uninformed and informed consumers.

The retailer that is not enrolled with the infomediary $D_{1}$ makes all its sales at its physical store. $D_{2}$ makes some online sales at the referral price, $P_{2}^{r}$, in the partially and fully informed segments and some offline sales to the low-valuation consumers in these two segments. It also makes some sales to uninformed consumers at its physical store. Sales made through the online referral mechanism incur no discovery cost. However, for every customer who walks in at the physical stores, retailers incur a discovery cost of $\delta$. The gross profit of $D_{2}$ (i.e., without accounting for the franchise and referral fees) is higher than that of $D_{1}$ for two reasons: (i) Its discovery costs decrease because some consumers shift on line, and (ii) its ability to price discriminate improves, and it can charge a monopoly price to the uninformed segment.

We use the superscript ${ }^{I}$ to indicate the values of various quantities for the case in which only the infomediary referral service is available. In equilibrium, the manufacturer will set its franchise fee, $F^{I}$, equal to the lower of the two gross profits, that is, the expected gross profit of $D_{1}$. The optimal referral fee charged by the infomediary will be the difference in expected gross profit between $D_{2}$ and $D_{1} \cdot{ }^{15}$ As a result

\footnotetext{
${ }^{15}$ We assume that the entire bargaining power in the negotiation between the infomediary and $D_{2}$ rests with the infomediary.
} 
of the enhanced price discrimination ability and the reduction in discovery costs it offers, the infomediary earns a positive profit. Therefore, the infomediary will strictly prefer to enroll only one retailer. ${ }^{16}$

We show that, if the number of partially informed consumers is low, or the proportion of high-valuation consumers is not too low, the optimal wholesale price of the manufacturer is $W^{I}=V^{l}$. The mathematical details of pricing strategies, manufacturer and infomediary fees, and profits of various parties are contained in Appendix A1 at the end of this paper.

Proposition 3. Suppose the proportion of partially informed consumers is not too high, or the proportion of high-valuation consumers is not too low, so that $\left(1-\alpha_{u}-\right.$ $\left.2 \alpha_{p}(1-\lambda)\right)>0$. Then,

(i) The optimal wholesale price for the manufacturer equals the valuation of the low-type consumer.

(ii) The optimal franchise fee is lower than in the offline case. The manufacturer's profit unambiguously falls as a result of the infomediary.

(iii) The optimal infomediary referral fee increases in the proportion of high-valuation consumers, the proportion of partially informed consumers, and the offline discovery cost.

(iv) Each retailer earns a zero profit.

(v) Total channel profit is higher than in the offline case if the proportion of partially informed consumers is sufficiently low.

Next, we comment on the effects of our assumptions on consumer search behavior and discovery cost on the above result.

REMARK 1.

- Consumer search behavior: In our base model, the partially informed segment $\alpha_{p}$ consists of moderate searchers. As a result of high search costs, these consumers obtain only an online price from the referral infomediary and an offline price from $D_{1}$. What are the implications of these consumers also obtaining an offline price from $D_{2}$ ? If they did, they would be equivalent to fully informed consumers. In such

As with the discussion in $\$ 3$ earlier, this assumption is easily modified to allow $D_{2}$ to capture some of the increase in its gross profit created by the infomediary.

${ }^{16}$ In practice, too, it is common for an infomediary to assign exclusive geographic territories to auto dealers; for example, see Moon (2000) and Scott-Morton et al. (2001, 2006). a scenario, we will have two distinct consumer segments: an uninformed segment of size $\left(\alpha_{u}\right)$ and a fully informed segment of size $\left(1-\alpha_{u}\right)$. We can determine the effects of such a change by setting $\alpha_{p}=0$ in the equilibrium expressions for the first two cases in Appendix A1.

Note that the condition in Proposition 3 is immediately satisfied when $\alpha_{p}=0$, so that the optimal wholesale price charged by the manufacturer remains $V^{l}$. If $\alpha_{p}=0$, we further have $F^{I}=F^{o}$; that is, the franchise fee charged by the manufacturer remains the same even when the infomediary is present. Since the wholesale price remains $V^{l}$, the manufacturer's profit remains the same as in the offline case, with $\Pi^{I}=\Pi^{o}$. Total channel profits increase by the infomediary's rent, $\left(\alpha_{u}\left(1-\alpha_{u}\right) /\left(2-\alpha_{u}\right)\right)\left(V^{h}-V^{l}\right)$.

- Zero discovery cost: Suppose the discovery cost $\delta$ were zero. The intuition of the model remains very similar, as can be seen by substituting $\delta=0$ into the equilibrium expressions in Appendix A1. In particular, the infomediary makes a positive profit, the manufacturer's profit is reduced, and total channel profit may be higher or lower, depending on the size of the partially informed segment.

- Fixed discovery cost: One may imagine that retailers incur some fixed costs in addition to the marginal costs of customer discovery. Our results are qualitatively unchanged with the inclusion of fixed discovery costs for retailers: The manufacturer's franchise fee decreases when the infomediary enters. The driving factor is that the manufacturer sets the franchise fee equal to the lower of the two retailer profits, and the infomediary captures the difference in their profits. Quantitatively, there will be a reduction in the franchise and referral fees by a total amount equivalent to the fixed cost of each retailer. Essentially, a fixed discovery cost has a similar effect as a reservation profit for a retailer.

- Correlated search: Suppose, as before, that limited Internet access and awareness leads to only highvaluation consumers searching in the online channel. In such a case where correlations between search behavior and valuations are endogenously determined, our analysis reveals that the online referral price is naturally set to target the high-valuation consumers. Consequently, as before, the referral price is randomized between $V^{h}$ and $V^{l}$. Thus, even if none 
of the low-valuation consumers search online, we find that it is still optimal for the retailer to use the referral service as the perfect screening mechanism. Moreover, our model can also be generalized to incorporate the situation where some low-valuation consumers in the partially and fully informed segments search online. Our analysis reveals that the nature of the equilibrium and the results remain unchanged. The table depicting the price search behavior is given in the online appendix.

We next discuss the importance of the condition $\left(1-\alpha_{u}-2 \alpha_{p}(1-\lambda)\right)>0$ in the statement of Proposition 3. In the absence of the infomediary, by always setting the wholesale price at $V^{l}$, the manufacturer is able to prevent aggravated price competition between the downstream retailers. When $W=V^{l}$, there is no price dispersion between the two dealers' prices for the low-valuation customers. Although this phenomenon still occurs in the presence of the infomediary, the wholesale price is set to $V^{l}$ only if the proportion of partially informed consumers or that of low-valuation consumers is low. For instance, for any $(1-\lambda) \leq 0.5$, the optimality of this wholesale price will hold. Similarly, the condition holds for $\lambda<0.5$ if the number of fully informed customers outnumbers the number of partially informed customers.

Suppose the manufacturer chooses a wholesale price $W<V^{l}$. As shown in Lemma 1 (which is in the online appendix), if the size of the partially informed segment $\left(\alpha_{p}\right)$ increases, $D_{1}$ offers a higher price on average to offline low-valuation consumers. This in turn allows the manufacturer to increase the franchise fee. If there are enough partially informed consumers, the gains from thus increasing the franchise fee can outweigh the losses from a lower wholesale price, to the extent that the manufacturer finds it optimal to set $W<V^{l}$.

In sum, the entry of the infomediary leads to an increase in the gross profit of the enrolled retailer and a corresponding decrease in the gross profit of the other retailer. This in turn leads to a lower franchise fee and a decrease in the manufacturer's profits.

\section{Manufacturer Establishes a Referral Service}

Next, we consider the scenario in which the manufacturer sets up its own digitally enabled referral service.
We assume that the manufacturer enrolls both retailers. This reconciles well with practice: Manufacturers such as General Motors (GM) Nissan, and Ford follow a nonexclusive strategy of enrolling retailers in their respective referral services, GMbuypower.com, Nissandriven.com, and Forddirect.com. ${ }^{17}$ As before, we only consider the case of the infomediary enrolling one retailer, $D_{2}$. If the infomediary enrolls both retailers, the logic of the infomediary-only case goes through, and the retailers earns zero profit. Hence, the infomediary will not enroll both retailers.

In each of the previous search segments, a proportion $\beta$ of the consumers (the "physical segment") continues to visit the physical stores, and the remaining proportion, $1-\beta$ (the "Web segment"), goes to the corresponding retailer via the manufacturer referral website.

The stages in this game are as follows: At Stage 1, the manufacturer sets the franchise fee, $F$, and the wholesale price, $W$, and establishes a referral website. Next, at Stage 2, the referral infomediary enrolls $D_{2}$ and sets a referral fee, $K$. At Stage 3, retailers simultaneously choose prices. $D_{1}$ chooses $\left(P_{1}\left(V^{h}\right), P_{1}\left(V^{l}\right)\right)$ for offline consumers and $P_{1}^{m}$ for online consumers who come through the manufacturer website. $D_{2}$ chooses $\left(P_{2}\left(V^{h}\right), P_{2}\left(V^{l}\right)\right)$ for offline consumers $P_{2}^{m}$ for online consumers who come via the manufacturer website, and $P_{2}^{r}$ for online consumers who come via the referral infomediary. In the final stage, consumers decide which product to buy.

We allow the manufacturer to move first to capture the notion that it has significant market power and can establish its franchise fee to capture rents from the retailers. The infomediary has less market power and is, in a sense, the residual claimant on the profit of $D_{2}$. The prices seen by consumers in different market segments are shown in Table 4.

Each retailer continues to observe the type of consumer at the physical store (i.e., in each of the four subsegments of the physical segment $\beta$ ) and can quote a price to these consumers that depends on

\footnotetext{
${ }^{17}$ Clicking on the link to find a dealership on these websites yields multiple dealer options, all with e-mail and/or phone contacts. In $\S 8.3$, we highlight why the manufacturer is content enrolling both retailers rather than just enrolling $D_{1}$ (the retailer not enrolled with the infomediary).
} 
Table 4 Different Prices Observed by Each Consumer Segment

\begin{tabular}{lcccccccc}
\hline Types & $\beta \alpha_{u} / 2$ & $(1-\beta) \alpha_{u} / 2$ & $\beta \alpha_{u} / 2$ & $(1-\beta) \alpha_{u} / 2$ & $\beta \alpha_{p}$ & $(1-\beta) \alpha_{p}$ & $\beta\left(1-\alpha_{u}-\alpha_{p}\right)$ & $(1-\beta)\left(1-\alpha_{u}-\alpha_{p}\right)$ \\
\hline$V^{h}$ & $P_{1}\left(V^{h}\right)$ & $P_{1}^{m}$ & $P_{2}\left(V^{h}\right)$ & $P_{2}^{m}$ & $P_{1}\left(V^{h}\right), P_{2}^{r}$ & $P_{1}^{m}, P_{2}^{r}$ & $P_{1}\left(V^{h}\right), P_{2}\left(V^{h}\right), P_{2}^{r}$ & $P_{1}^{m}, P_{2}^{m}, P_{2}^{r}$ \\
$V^{\prime}$ & $P_{1}\left(V^{\prime}\right)$ & $P_{1}^{m}$ & $P_{2}\left(V^{\prime}\right)$ & $P_{2}^{m}$ & $P_{1}\left(V^{\prime}\right), P_{2}^{r}$ & $P_{2}^{m}, P_{2}^{r}$ & $P_{1}\left(V^{\prime}\right), P_{2}\left(V^{\prime}\right), P_{2}^{r}$ & $P_{1}^{m}, P_{2}^{m}, P_{2}^{r}$ \\
\hline
\end{tabular}

their type. However, as before, the retailers do not observe the types of the consumers who come via the manufacturer website. Hence, in the Web $(1-\beta)$ sub-segments, a given retailer must quote the same prices to both consumer types. We denote the online (manufacturer referral) prices of the two retailers as $P_{1}^{m}$ and $P_{2}^{m}$.

In Lemma 1 in the online appendix, we exhibit the equilibrium prices and retailer gross profit when the wholesale price $W$ is close to $V^{l}$. As before, at lower wholesale prices, the manufacturer profit is lower, too. In equilibrium, the price $D_{2}$ offers to consumers who use the infomediary, $P_{2}^{r}$, follows the same distribution as in the world with only an infomediary and no manufacturer referrals. Consider the extreme case with only Web consumers (i.e., $\beta=0$ ). The structure of the game is then similar to the one with only an infomediary referral service. However, because all consumers here are on line, no information about consumer valuations is available. Because the proportion of highvaluation consumers is low (recall that $\lambda \leq V^{l} / V^{h}$ ), both retailers act as if all consumers had low valuations and randomize referral prices with a highest price of $V^{l}$. Hence, the price distribution function remains the same as with only the infomediary referral service.

This property then helps determine the rest of the equilibrium strategies. In particular, given the structure of the new game, it implies that the prices $P_{1}\left(V^{l}\right), P_{1}\left(V^{h}\right), P_{2}\left(V^{l}\right)$, and $P_{2}\left(V^{h}\right)$ are set as in the earlier game in $\S 4$. Finally, $P_{1}^{m}$ is chosen randomly over an interval as well. The equilibrium exhibited below holds for all values of $\beta \in[0,1]$. Note that if $\beta=1$, we are back to the game of Table 3 , and the equilibrium strategies are equivalent to those for the case in which only the infomediary referral service exists, as exhibited in Lemma 1 (which is part of the online appendix).

Intuitively, $D_{2}$ charges an infomediary referral price randomly chosen over the interval $\left[W+\left(\alpha_{u}\left(V^{h}-\right.\right.\right.$ $\left.W)) /\left(2-\alpha_{u}\right), V^{h}\right]$ and charges a higher price $V^{h}$ to referrals from the manufacturer's website. Because all partially and fully informed consumers who approach $D_{2}$ through the manufacturer site also seek a price via the infomediary, $D_{2}$ is effectively able to use the infomediary referral price as a price discrimination tool, to separate out informed consumers, while it charges the maximum feasible price $V^{h}$ to Web-based uninformed consumers. Similarly, $D_{1}$ charges prices higher than $V^{l}$ to Web-based consumers, effectively shutting out low-valuation consumers from buying over the Web.

Online referral services effectively serve as a price discrimination tool for retailers. Although information about consumer valuations is unavailable on line, retailers are able to screen out low-valuation consumers and sell only to high-valuation consumers in the online channel. Therefore, despite making no assumption about correlation between online search behavior and consumer valuations, our model implies that online purchases and consumer valuations are indeed correlated, because only high-valuation consumers buy on line. ${ }^{18}$

What wholesale price will the manufacturer charge? We show that if the proportion of consumers who remain offline, $\beta$, and the proportion of high-valuation consumers, $\lambda$, is sufficiently high, the manufacturer will again charge the wholesale price $V^{l}$. Intuitively, when the manufacturer chooses a higher wholesale price, the equilibrium of the retailers' pricing game leads to manufacturer referral prices greater than $V^{l}$. Consequently, uninformed low-valuation buyers in the Web segment, who only check online manufacturer referral prices, are shut out of the market, and

\footnotetext{
${ }^{18}$ Note that our model predicts that, on average, online searchers (not necessarily online buyers) pay lower prices. Online buyers have high valuation and obtain lower prices than offline highvaluation customers but higher prices than offline low-valuation customers. For some model parameters, the average online price will be lower than the average offline price (e.g., if the proportion of online consumers is relatively low).
} 
the manufacturer's total sales fall. The cost of losing these consumers is lower if $\beta$ is lower (so there are fewer consumers in this subsegment) or $\lambda$ is higher (so there are fewer low-valuation consumers). Thus, as $\beta$ declines toward zero, both manufacturer profit and total profit in the supply chain increase. The mathematical details of all relevant expressions are shown in Appendix A1 at the end of the paper.

Proposition 4. Suppose the proportion of partially informed consumers is not too high, and the proportion of high-type consumers is not too low, so that $\left[\lambda\left(1-\alpha_{u}\right)+\right.$ $\left.\beta(1-\lambda)\left(1-\alpha_{u}-2 \alpha_{p}\right)\right]>0$. Then,

(i) The optimal wholesale price for the manufacturer equals the valuation of the low-type consumer.

(ii) The optimal franchise fee is higher than in the infomediary case. Moreover, if the discovery cost is sufficiently high, the manufacturer earns a higher profit once it establishes its own referral service.

(iii) The optimal infomediary referral fee decreases compared to the case when there is only an infomediary in the market.

(iv) Each retailer earns a zero profit.

(v) If the offline discover cost is sufficiently high, total channel profit is higher than in the infomediary-only case.

Intuitively, the impetus toward an increased manufacturer profit comes from two sources. First, it levels the playing field between the two retailers by providing $D_{1}$ with a weapon to price discriminate between consumer segments online. Using the manufacturer's referral price $P_{1}^{m}, D_{1}$ is now able to compete more effectively against $D_{2}$ 's infomediary referral price $P_{2}^{r}$ for the partially and fully informed consumer segments. Second, there is a reduction in the discovery costs of $D_{1}$ as some consumers are served online. This increases profit in the supply chain and enables the manufacturer to extract this increased profit via an increase in the franchise fee that it charges the retailers. Because eventual profits of each retailer are nonnegative, there is no conflict of interest here between supply chain members. Thus, the strategic decision by the manufacturer to adopt a digitally enabled referral service affects both the level of profit in the supply chain and the allocation of profit among the members.

Next, we consider the effects of different consumer search behavior and discovery cost on the above equilibrium.

\section{REMARK 2.}

- Consumer search behavior: Suppose consumers in the $\alpha_{p}$ segment observed prices from both dealers, in addition to receiving a price via the infomediary referral service. This would be equivalent to a model in which $\alpha_{p}=0$; that is, there would be no partially informed segment. From the equilibrium expressions in Appendix A1, we observe that when $\alpha_{p}=0$, the manufacturer earns a higher profit as a result of its own website (i.e., $\Pi^{m}>\Pi^{I}$ ). However, (i) the infomediary's profit is the same as before, with $K^{m}=K^{I}$, and (ii) as mentioned in Remark 1, the manufacturer's profit when just the infomediary referral service exists is the same as its offline profit, because $\Pi^{I}=\Pi^{o}$. Note that, as with Proposition 3, the condition in Proposition 4 is immediately satisfied when $\alpha_{p}=0$, so the optimal wholesale price charged by the manufacturer remains $V^{l}$.

- Discovery cost: The discovery cost $\delta$ is clearly critical in establishing that the manufacturer gains when it sets up its own referral service (if $\delta=0$, then $\left.\Pi^{m}<\Pi^{I}\right)$. In the absence of a discovery cost, having consumers search the online channels provides no benefits to the manufacturer and conversely does not hurt the retailer. Thus, we see that the ability of dealers to discriminate on prices as a result of the market segmentation is critical to the success of the infomediary, whereas reducing the acquisition cost is critical to the success of the manufacturer.

- Correlated search: Suppose, as before, limited Internet access and awareness lead to only highvaluation consumers searching in the online channel. Once again, our analysis reveals no change in the qualitative nature of the results and analysis.

There are three key aspects of the manufacturer's own referral service. First, the condition in the statement of the Proposition $4,\left[\lambda\left(1-\alpha_{u}\right)+\beta(1-\lambda)\left(1-\alpha_{u}-\right.\right.$ $\left.\left.2 \alpha_{p}\right)\right]>0$, is satisfied whenever the size of the partially informed segment is sufficiently low (i.e., when $\alpha_{p}$ is close to zero) or whenever the proportion of highvaluation consumers is not too low. Further, if $\beta=1$, this condition reduces to the corresponding condition for the infomediary-only case: $\left[1-\alpha_{u}-2 \alpha_{p}(1-\lambda)\right]>0$.

Second, the trade-off for a manufacturer is that, although discovery costs in the channel are reduced as a result of its referral service, so are total sales. Because 
retailers use online referral services to shut out lowvaluation consumers, these consumers leave the channel altogether. Thus, total sales of the manufacturer are lower than in the previous cases. To ensure that the manufacturer earns a higher profit after establishing its own referral service, the number of such online low-valuation consumers must be sufficiently low (i.e., the proportion of offline consumers, $\beta$, must be sufficiently high).

Third, compared to the infomediary-only case, the manufacturer improves its profit by establishing its own referral services, in part by diverting profit away from the infomediary. This is demonstrated by the existence of a range of discovery cost $\delta$ for which channel profit decreases once the manufacturer referral service is set up, but the manufacturer's profit increases. Thus, the referral service plays a strategic role in the manufacturer's response to the existence of an infomediary.

Proposition 5. (i) The establishment of the referral service leads to the optimal wholesale price being high (i.e., at least as high as the valuation of the low-type consumer) over a larger range of parameter values.

(ii) Over some range of discovery cost, channel profit decreases, but manufacturer profit increases because of the manufacturer referral service.

Thus, the establishment of a referral service by the manufacturer permits a wider leeway to set a high wholesale price. The flexibility in setting the wholesale price accrues from the heterogeneity in consumer valuations. If all consumers were homogeneous in their valuations, the manufacturer's profit-maximizing wholesale price would be equal across the different scenarios (regardless of the presence of the infomediary).

Next, we consider the effects of the manufacturer referral services on the expected sales, prices, and profits of the two retailers. Given the structure of the equilibrium, the corresponding values for the physical segment are the same as in the infomediary-only case. We show below that, in the Web segment, $D_{2}$ (enrolled with the infomediary) has higher expected sales than $D_{1}$ (which is not enrolled with the infomediary). $D_{2}$ uses the infomediary as a price discrimination mechanism. It charges (on average) a low price to consumers referred by the infomediary and a high price $V^{h}$ to consumers referred by the manufacturer.
Proposition 6. (i) In the Web segment, $D_{2}$ (which is enrolled with the infomediary) has higher expected sales than $D_{1}$ (which is not).

(ii) The average manufacturer referral price of $D_{2}$ is greater than its average infomediary referral price.

Using numerical analysis, we can show that there is a large region in the parameter space wherein $D_{1}{ }^{\prime} \mathrm{s}$ manufacturer referral price is higher than $D_{2}$ 's infomediary referral price. The difference between the manufacturer and infomediary referral prices in our model is consistent with empirical evidence found by Scott-Morton et al. (2006) for the auto industry. They find that while the referral process of third-party infomediaries helps consumers get lower prices, a referral from a manufacturer website to one of the manufacturer's dealerships results in higher prices.

In the offline segment, the market shares of the two retailers remain the same as in the world with an infomediary but no manufacturer referrals. That is, $D_{2}$ retains a higher market share in the offline segment. In the Web segments, we see that $D_{2}$ again experiences a higher market share. Hence, there is a strong incentive for $D_{2}$ (or more generally, for any one retailer) to enroll with the infomediary. An affiliation with the referral infomediary provides the retailer with the ability to price discriminate in its uninformed (captive) segment. It charges a monopoly price to all offline consumers and uses the referral price to compete with the other retailer online. This increases its expected sales. Conversely, the retailer who remains out of the infomediary referral services incurs a loss in expected sales and profits.

\section{Manufacturer Eliminates the Referral Infomediary}

As shown earlier, the manufacturer is hurt (i.e., it has a lower profit) by the presence of the infomediary. We show in this section that it is feasible for the manufacturer to choose a wholesale price that would eliminate the referral infomediary altogether. However, this is prohibitively costly for the manufacturer, which prefers to allow the infomediary to remain in the supply chain. In the context of the auto industry, there is no evidence (anecdotal or otherwise) of 
an OEM attempting to eliminate a third-party referral infomediary. ${ }^{19}$

Recall that the benefit to a retailer of enrolling with the infomediary is twofold: enhanced price discrimination and reduction in discovery cost. If the manufacturer wishes to eliminate the referral infomediary, it must set a wholesale price $W$ equal to $V^{h}$. Any wholesale price below $V^{h}$ leads to price dispersion, which will facilitate price discrimination by $D_{2}$, the retailer enrolled with the infomediary. In turn, this leads to a positive profit for $D_{2}$ after paying the manufacturer's franchise fee, and the infomediary can extract this profit through its referral fee. This prevents the infomediary from unraveling.

On the other hand, if $W=V^{h}$, each retailer must set both offline and online prices equal to $V^{h}$. A retail price below $V^{h}$ leads to a loss on each sale, whereas setting a retail price above $V^{h}$ leads to no sales at all. When retail prices are set to $V^{h}$, low-valuation consumers are completely shut out of the market, and only high-valuation consumers buy. Thus, total sales are equal to $\lambda$. Further, total discovery costs are $\beta\left(2-\alpha_{u}\right) \delta$. Thus, the manufacturer's overall profit is $\lambda V^{h}-\beta\left(2-\alpha_{u}\right) \delta$. We show that if the proportion of offline consumers is not too low, the manufacturer has a higher profit when it allows the infomediary to coexist.

Proposition 7. Suppose the proportion of offline consumers is not too low; specifically, $\beta \geq\left(1-\alpha_{u}\right)(\lambda /(1-$ $\lambda))\left(V^{h}-V^{l}\right) / V^{l}$. Then the manufacturer has a lower profit if it eliminates the infomediary than if it allows the infomediary to coexist in the supply chain.

The condition in the proposition is also satisfied if the proportion of high-valuation consumers, $\lambda$, is sufficiently low. The intuition is that, to eliminate the infomediary, the manufacturer must set the wholesale price to $V^{h}$, which eliminates all low-valuation consumers. With the manufacturer's referral service, online low-valuation consumers in the $(1-\beta)$ segment are already eliminated, because online prices

\footnotetext{
${ }^{19}$ There have been attempts by auto manufacturers to forge strategic tie-ups with independent intermediaries. In 2001, GM attempted an alliance with Autobytel and Ford with MSN Carpoint (now known as MSN Autos). Both attempts were abandoned within a few months, with the OEMs instead building their own referral services.
}

exceed $V^{l}$. Thus, the incremental cost of setting $W=V^{h}$ is that offline low-valuation consumers also leave the market. This cost is naturally higher when the proportion of offline consumers is higher or the proportion of high-valuation consumers is lower.

Note that we do not consider scenarios in which the manufacturer charges a different franchise fee for each retailer. The Robinson-Patman Act prohibits manufacturers from discriminating across symmetric retailers. However, if there were some inherent asymmetry between the retailers, such as differences in cost structures, it is possible the manufacturer would charge different franchise fees to each retailer. One consequence of such an action could be the unraveling of the infomediary.

\section{Numerical Corroboration with Empirical Evidence}

We now show that our model generates quantitative results in accordance with anecdotal evidence. We do this by choosing parameter values from previous empirical literature and assessing the resulting price dispersion and the implied closing ratios (CRs) for retailer sales.

First, consider the sizes of the different market segments. Klein and Ford (2003) in their survey of auto buyers point out that about $58 \%$ of consumers do not search at all. Additionally, about $22 \%$ of the buyers exhibit moderate search behavior by searching some of the offline and online sources, and about $20 \%$ are highly active information seekers who obtain multiple quotes from all possible sources. This sort of consumer search behavior is corroborated by a J.D. Powers study (2000), which finds that about $41 \%$ of consumers surveyed used a referral service while buying a car, whereas the remaining 59\% did not (Rayport et al. 1998). Based on these data sources, we vary the value of $\alpha_{u}$, the size of the uninformed segment in our model, from 0 to 0.5. Further, Ratchford et al. (2003) find that $40 \%$ of buyers used online sources (i.e., manufacturer and third-party websites). Based on this we vary the proportion of offline consumers, $\beta$, from 0.6 to 1 . We vary the proportion of high-valuation buyers, $\lambda$, from 0 to 0.4 . Based on actual average gross margin of dealers (see Moon 2000), we take $\left(V^{h}-W\right)$ to be $\$ 3,500$ and $\left(V^{l}-W\right)$ to be $\$ 1,500$. 
Using these ranges for the parameters, we compute the price dispersion between online and offline price, the infomediary referral fee, and CRs. We choose $\alpha_{u} \in$ $[0,0.5]$ and determine the critical value of discovery cost, $\delta_{c}$. If the actual discovery cost, $\delta$, lies above this threshold, the manufacturer's profit increases after the manufacturer establishes its own referral service. We find that the maximal $\delta_{c}$ over this parameter range is $\$ 700$. This is close to the empirical estimates of ScottMorton et al. (2001), who show that the average cost to a dealer of an offline sale is $\$ 675$ higher than the cost of a sale via Autobytel.

Next we consider the price differences between offline and online channels. Scott-Morton et al. (2001, 2003) show that the average Autobytel customer sees a contract price about $\$ 500$ lower than the nonreferral offline prices. For the parameters we consider, the difference between the expected offline price (for low types) and the expected online infomediary referral price quotes (for $D_{2}$, the retailer associated with the infomediary) ranges between $\$ 400$ and $\$ 650$.

Finally, we numerically estimate the CRs of the referral services. The $C R$ is defined as

$$
C R=\frac{\text { Number of units sold }}{\text { Number of referrals received }} .
$$

This statistic forms a pivotal basis on which a retailer is evaluated by the referral infomediary. For example, in 1998-1999, Autobytel dropped around 250 dealers ( $10 \%$ of its dealer base) because of negative customer feedback and low CRs (see Moon 2000). We find that the CR of $D_{2}$ via manufacturer referral services ranges between $10 \%$ and $30 \%$. According to anecdotal evidence, Forddirect.com has a CR of $17 \%$, and GMBuypower.com has a CR of around $25 \% .{ }^{20}$ Between May and October, 2001, GM tested a system of providing sales leads or referrals to Chevrolet dealers in the Washington, D.C., area. According to GM, about $25 \%$ of such referrals were closed, which was roughly the same proportion as that of walk-in leads closed in physical showrooms. The numerical parameterization, therefore, highlights the robustness of the model and the main results. The CR from the infomediary referral price in our model is between $20 \%$ and $30 \%$,

\footnotetext{
${ }^{20}$ www.trilogy.com/Sections/Industries/Automotive/Customers/ FordDirect-Success-Story.cfm.
}

slightly higher than industry evidence. ${ }^{21}$ One reason for this may be that our model does not consider interbrand competition. If consumers search among multiple brands before completing a purchase, there will be multiple referrals for a single sale, thereby resulting in lower CRs.

\section{Extensions}

Because online markets are complex and rapidly evolving, several extensions of our model merit further discussions. In this section, we consider the robustness of our model to changes in several of its features.

\subsection{Manufacturer-Induced Online Price Discrimination}

Suppose an alternate online technology is available whereby manufacturers can facilitate online price discrimination by retailers. ${ }^{22}$ As shown in $\$ 5$, retailers lose information about consumer valuations on line and charge online prices higher than $V^{l}$. As a result, online low-valuation consumers of mass $(1-\beta)(1-\lambda)$ are shut out of the market. If, say, $D_{1}$ could identify these consumers on line and set a price $P_{1}^{m}$ equal to their valuation $V^{l}$, its overall sales would increase. Though the dealer's gross profit would be unchanged (because the marginal cost of the good to the dealer is also $V^{l}$ ), manufacturer and supply chain profit would increase by an amount of $(1-\beta)(1-\lambda) V^{l}$. This increase would accrue from the per unit fee component of the two-part tariff. Thus, online price discrimination induced by the manufacturer can lead to even greater profits than those attainable in the benchmark case.

\subsection{Imperfect Information About Consumer Valuations}

For analytical tractability, we have assumed that, in the offline channel, retailers can perfectly infer consumer valuations. An alternative is to assume that retailers observe the valuation with noise. There are

\footnotetext{
${ }^{21}$ http://www.investorville.com/ubb/Forum2/HTML/000040.html.

${ }^{22}$ If competing retailers are also differentiated on customer service (as auto dealers often are), the interplay between price discrimination and customer service can affect their incentives to adopt personalized pricing policies. See, for example, Choudhary et al. (2005).
} 
two possibilities in such a situation: First, if consumers cannot bargain, sometimes the price will be set above the valuation of a low-valuation consumer (note that the price will never exceed the valuation of a high-valuation consumer). Hence, low-valuation consumers will sometimes choose to not purchase, because they may be offered prices by both retailers in excess of their valuations. This will reduce the gross profit of the retailers a little and thereby reduce the manufacturer's franchise fee.

However, several results of the paper will still go through: (i) The infomediary will still enable price discrimination across search segments and benefit from enrolling only one retailer, (ii) the manufacturer offering referral services will increase its profits by extracting surplus from the infomediary, and (iii) offering its own referral services will allow the manufacturer to set the wholesale price equal to the valuation of the low-type consumers over a larger range of parameters.

\subsection{Manufacturer Enrolls Only One Retailer}

One difference between manufacturer and infomediary referral services is that our manufacturer enrolls both retailers. What if, instead, the manufacturer enrolled only $D_{1}{ }^{23}$ We find that the manufacturer is equally well off enrolling only $D_{1}$ as it is enrolling both retailers. Our model hence provides a rationale as to why manufacturers follow a nonexclusive practice of enrolling multiple retailers.

If $D_{2}$ is not enrolled by the manufacturer, the only segments affected are the uninformed (captive) segment of $D_{2}$ and the fully informed consumers in the $\beta$ segment. The former clearly does not affect profits of $D_{1}$ in any way. Consider the latter. Recall that, in our equilibrium, $P_{2}^{m}$ is set to $V^{h}$, whereas $P_{1}^{m}$ and $P_{2}^{r}$ are randomized over $\left(\hat{P}^{h}, V^{h}\right)$. Consequently, $D_{1}$ effectively competes only with the infomediary referral price, $P_{2}^{r}$, and not with the manufacturer referral price, $P_{2}^{m}$, of $D_{2}$. Hence, $D_{1}$ 's sales to the latter segment are unchanged. Therefore, the profits of $D_{1}$ and thus the manufacturer's profits are unchanged if only $D_{1}$ is enrolled.

\footnotetext{
${ }^{23}$ It is trivial to show that enrolling only $D_{2}$ leads to a further decrease in $D_{1}$ 's profits, and thus results in lower manufacturer profits.
}

However, such a move does affect $D_{2}$ 's gross profits; these actually increase, because in its captive segment $D_{2}$ can now sell to low-valuation consumers off line at $P_{2}\left(V^{l}\right)$, rather than losing the online proportion $\beta$. This increase in $D_{2}$ 's gross profit is then captured by the infomediary, providing the manufacturer with a stronger incentive to decrease the infomediary's channel power.

\section{Conclusion and Limitations}

Our analysis suggests that when manufacturers in an extended enterprise cannot sell directly to consumers, either because of legal restrictions or to avoid direct conflict with their retailers, the digitally enabled referral service model is a strategic tool for them to increase their channel power and profits. In particular, the referral mechanism, by diverting traffic from offline to online channels, both increases retailers' ability to price discriminate across different consumer search segments and leads to a reduction in customer discovery costs. There is a trade-off, because retailers have to forgo information about valuations of consumers who only appear online.

Our model implies that the entry of third-party referral services in the midstream part of an extended enterprise can hurt manufacturers in both components of its contract with downstream retailers-by reducing its franchise fee and by squeezing its optimal wholesale price. When a manufacturer establishes its own online referral service, it counteracts both effects. The extent to which overall supply chain profits increase depends on the relative composition of consumer types in the market and their valuations. In practice, we expect the actual allocation of profits among supply chain members to vary, depending on the bargaining power of each agent.

Interestingly, we derive consumer purchase behavior endogenously, without assuming any relationship between search behavior and valuations ex ante. That is, based on the pricing strategies of retailers, our model suggests that there will be an endogenous correlation between purchases over the Web and consumer valuations. Another implication of our model is that in markets with relatively inelastic market demand or high brand loyalty, the optimal wholesale price can be higher than the manufacturer's marginal cost. Specifically, in the model, setting the wholesale 
price to the marginal cost instead of the valuation of low-type consumers aggravates price competition between downstream retailers, reducing the manufacturer's franchise fee.

What are the implications of our paper for retailers in an extended enterprise? In our model, we do not consider the possibility of retailers establishing their own Web services to attract consumer traffic and sales. Suppose each retailer sets up its own website to directly appeal to consumers, in addition to enrolling with the referral service. There are two potential implications of such a phenomenon. Intuitively, one consequence is an increase in the bargaining power of the retailers vis-à-vis the manufacturer and infomediary, which will transfer some of the profit in the supply chain to the retailers. The qualitative nature of our results holds under this formulation, though the quantitative magnitudes of profit change.

Another aspect of retailer websites is that these are equivalent to an investment in customer acquisition, similar to regular mass media advertising or marketing campaigns. In a model of price dispersion with mixed strategies, Hann et al. (2005) show that if firms invest in customer acquisition before setting prices, the unique mixed strategy equilibrium is asymmetric, with one firm acquiring twice as many customers as the other. In our benchmark model this is equivalent to having one retailer with a larger captive segment of uninformed consumers and the other one having a smaller captive segment. Potentially, this would affect the incentives of each dealer to sign with the infomediary; the dealer with a smaller captive segment will be more interested in the price discrimination possibilities offered by the infomediary. Again, such an extension only affects the quantitative magnitudes of prices, sales, and profit in equilibrium, without changing the qualitative nature of the results.

Finally, our analysis suggests some strategies manufacturers can adopt to maximize supply chain profits. First, strategic alliances with online portals, such as those of GM with AOL and Ford with Yahoo, can direct a larger number of consumers to manufacturersponsored referral services. Of course, infomediaries will also benefit from similar tie-ups. Because they direct so much of online search, the major search engines and portals can be expected to emerge as important players in the referral services area. Second, manufacturers can invest electronic customer relationship management (e-CRM) packages to collect more information about consumers who visit their referral services to infer consumer valuations online. Firms such as Nissan and GM are investing in technologies to enable such online personalized pricing initiatives.

The restriction to a single manufacturer and a single infomediary represents a limitation of our model. In many instances, referral infomediaries partner with multiple manufacturers. Interbrand competition or price competition between infomediaries can impact contracts between the different entities in the value chain and hence the division of profit across different parts of the chain. Our conjecture is that the qualitative nature of the results will remain unaffected, but it would be interesting to formally model this scenario.

Another limitation is that we do not consider the effect of infomediaries on the mix of buyers itself. Our model assumes an exogenous demand from "uninformed" and "informed" customers whose market sizes are driven by implicit differences in search costs. The sizes of various market segments may well change endogenously with the availability of competing thirdparty infomediaries. For example, what would happen if there were a disproportionate representation of one type of consumer in the online segments? Suppose only high-valuation consumers searched on line. Then our results would still hold, because online prices are already targeted only toward high-valuation consumers in our current model. On the other hand, if only low-valuation consumers searched on line, online prices would be lower, because high-valuation consumers would have already screened themselves out from accessing referral services. A detailed analysis of these possibilities is beyond the scope of our paper but can be a fruitful area for future research.

Finally, we do not allow consumers to bargain over the price when they visit a physical retailer store. It is possible that consumers who are partially and fully informed choose to bargain, because they observe multiple prices and will have an online price in hand before they obtain an offline price. Once we allow for such bargaining between consumers and retailers in the supply chain, the online prices obtained by even high-valuation consumers may be higher 
than the offline prices obtained via bargaining. Whatever price is charged online, a consumer will obtain a lower offline price from the other dealer. Thus, no sales occur via the infomediary, which can no longer exist. Therefore, the existence of the infomediary necessarily requires some imperfections in consumers' bargaining abilities.

\section{Acknowledgments}

The authors thank Ram Rao, Anthony Dukes, Philipp Afeche, seminar participants at Carnegie Mellon University, New York University, University of Maryland, University of Connecticut, University of California, Irvine, Tulane University, University of Southern California, University of Arizona, and participants at the Conference on Information Systems \& Technology (CIST) 2002, Workshop on Information Systems \& Economics (WISE) 2002, and the International Conference on E-Commerce (ICEC) 2003 for extremely useful feedback. The authors also thank Senior Editor M. S. Krishnan and three anonymous reviewers for suggestions that helped to improve this paper. The first author acknowledges the support of NSF Career Grant IIS0643847.

\section{Appendix A1. Outcomes Under Different Scenarios}

\section{No referral services.}

- Wholesale price: $W^{o}=V^{l}$.

- Retail prices: $P_{1}\left(V^{l}\right)=P_{2}\left(V^{l}\right)=V^{l}$ where

$$
P_{1}\left(V^{h}\right), P_{2}\left(V^{h}\right) \text { randomized over }\left[\hat{P}^{h}, V^{h}\right] \text {, }
$$

$$
\begin{aligned}
\hat{P}^{h} & =V^{l}+\frac{\alpha_{u}}{2-\alpha_{u}}\left(V^{h}-V^{l}\right), \quad \text { and } \\
G^{h}(P) & =\operatorname{Prob}\left(P^{h}>P\right)=\frac{\alpha_{u}+\alpha_{p}}{2\left(1-\alpha_{u}-\alpha_{p}\right)}\left(\frac{V^{h}-P}{P-V^{l}}\right) .
\end{aligned}
$$

- Franchise fee: $F^{o}=\left(\left(\alpha_{u}+\alpha_{p}\right) / 2\right) \lambda\left(V^{h}-V^{l}\right)-\left(1-\left(\alpha_{u}+\right.\right.$ $\left.\left.\alpha_{p}\right) / 2\right) \delta$.

- Manufacturer's expected profit: $\Pi^{o}=V^{l}+\left(\alpha_{u}+\right.$ $\left.\alpha_{p}\right) \lambda\left(V^{h}-V^{l}\right)-\left(2-\alpha_{u}-\alpha_{p}\right) \delta$.

- Total channel profit: $\mathscr{S}^{o}=V^{l}+\left(\alpha_{u}+\alpha_{p}\right) \lambda\left(V^{h}-V^{l}\right)-$ $\left(2-\alpha_{u}-\alpha_{p}\right) \delta$.

2. Infomediary referrals only. The following is an equilibrium if $\left[1-\alpha_{u}-2 \alpha_{p}(1-\lambda)\right]>0$.

- Wholesale price: $W^{I}=V^{l}$.

- Retail prices: $P_{1}\left(V^{l}\right)=P_{2}\left(V^{l}\right)=V^{l}$

$$
P_{2}\left(V^{h}\right)=V^{h} \text {, and } P_{1}\left(V^{h}\right), P_{2}^{r} \text { randomly }
$$
chosen over $\left[\hat{P}^{h}, V^{h}\right]$, where

$$
\begin{aligned}
\hat{P}^{h} & =V^{l}+\frac{\alpha_{u}}{\left(2-\alpha_{u}\right)}\left(V^{h}-V^{l}\right), G_{1}^{h}(P)=\operatorname{Prob}\left(P_{1}\left(V^{h}\right)>P\right) \\
& =\frac{\alpha_{u}}{2-\alpha_{u}} \frac{V^{h}-P}{P-V^{l}}
\end{aligned}
$$

with a mass point $\alpha_{u} /\left(2-\alpha_{u}\right)$ at $V^{h}$, and

$$
G_{2}^{r}(P)=\operatorname{Prob}\left(P_{2}^{r}>P\right)=\frac{\alpha_{u}}{2\left(1-\alpha_{u}\right)} \frac{V^{h}-P}{\left.P-V^{l}\right)} .
$$

- Infomediary fee: $K^{I}=\lambda\left(\alpha_{u}\left(1-\alpha_{u}\right) /\left(2-\alpha_{u}\right)\right)\left(V^{h}-\right.$ $\left.V^{l}\right)+\alpha_{p} \delta$.

- Franchise fee: $F^{I}=F^{o}-\left(\alpha_{p} / 2\right)\left[\lambda\left(V^{h}-V^{l}\right)+\delta\right]$.

- Manufacturer profit: $\Pi^{I}=\Pi^{o}-\alpha_{p}\left[\lambda\left(V^{h}-V^{l}\right)+\delta\right]$.

- Total channel profit: $\mathscr{S}^{I}=\mathscr{S}^{o}+\lambda\left[\alpha_{u}\left(1-\alpha_{u}\right) /\left(2-\alpha_{u}\right)-\right.$ $\left.\alpha_{p}\right]\left(V^{h}-V^{l}\right)$.

3. Both manufacturer and infomediary referrals present. The equilibrium below holds if (i) $\beta$, the proportion of offline consumers is sufficiently high, and (ii) $\left[\lambda\left(1-\alpha_{u}\right)+\right.$ $\left.\beta(1-\lambda)\left(1-\alpha_{u}-2 \alpha_{p}\right)\right]>0$.

- Wholesale price: $W^{m}=V^{l}$.

- Retail prices: $P_{1}\left(V^{l}\right), P_{1}\left(V^{h}\right), P_{2}\left(V^{l}\right), P_{2}\left(V^{h}\right)$, and $P_{2}^{r}$ all set as in infomediary-only case. $\left[\hat{P}^{h}, V^{h}\right]$, where

$P_{2}^{m}=V^{h}$, and $P_{1}^{m}$ randomly chosen over

$$
\begin{aligned}
\hat{P}^{h} & =W+\frac{\alpha_{u}\left(V^{h}-W\right)}{\left(2-\alpha_{u}\right)} \text { and } \\
G_{1}^{m}(P) & =\operatorname{Prob}\left(P_{1}^{m}>P\right)=\frac{\alpha_{u}}{2-\alpha_{u}} \frac{V^{h}-P}{P-V^{l}},
\end{aligned}
$$

with a mass point $\alpha_{u} /\left(2-\alpha_{u}\right)$ at $V^{h}$.

- Infomediary fee: $K^{m}=K^{I}-(1-\beta) \alpha_{p} \delta$.

- Franchise fee: $F^{m}=F^{I}+(1-\beta)\left(1-\left(\alpha_{u} / 2\right)\right) \delta$.

- Manufacturer profit: $\Pi^{m}=\Pi^{I}+(1-\beta)\left[\left(2-\alpha_{u}\right) \delta-\right.$ $\left.(1-\lambda) V^{l}\right]$.

- Total channel profit: $\mathscr{S}^{m}=\mathscr{S}^{I}+(1-\beta)\left[\left(2-\alpha_{u}-\alpha_{p}\right)\right.$ $\left.\delta-(1-\lambda) V^{l}\right]$.

\section{References}

Bandyopadhyay, S., J. Barron, A. Chaturvedi. 2005. Competition among sellers in online exchanges. Inform. Systems Res. 16(1) $47-60$.

Baye, M., J. Morgan. 2001. Information gatekeepers on the internet and the competitiveness of homogeneous product markets. Amer. Econom. Rev. 91(3) 454-474.

Cattin, P., G. Punj. 1983. Identifying the characteristics of single retail (dealer) visit new automobile buyers. R. P. Bagozzi, A. M. Tybout, eds. Advances in Consumer Research, Vol. 10, 383-388.

Chen, Y., G. Iyer, V. Padmanabhan. 2002. Referral infomediaries. Marketing Sci. 21(4) 412-434.

Choudhary, V., A. Ghose, T. Mukhopadhyay, U. Rajan. 2005. Personalized pricing and quality differentiation. Management Sci. 51(7) 1120-1130.

Choudhury, V., W. Xia, N. Venkataraman, J. Henderson. 1999. A resource-based theory of network structures. Research in Strategic Management and Information Technology. JAI Press, Inc., Greenwich, CT, 55-56.

Chwelos, P., I. Benbasat, A. Dexter. 2001. Research report: Empirical test of an EDI adoption model. Inform. Systems Res. 12(3) 304-321. 
Downs, A. 1961. A theory of consumer efficiency. J. Retailing 39 6-12.

Forman, C., A. Ghose, A. Goldfarb. 2006. Competition between local and electronic markets: How the benefit of buying online depends on where you live. Working paper, New York University, New York.

Ghose, A., R. Krishnan, R. Telang. 2005. Effect of electronic secondary markets on the supply chain. J. Management Inform. Systems (Fall) 91-120.

Granados, N., A. Gupta, R. Kauffman. 2006. Market transparency and multi-channel strategy: Modeling and empirical analysis of online travel agents. Working paper, University of Minnesota.

Hann, I., K. Hui, S. Lee, I. Png. 2005. Sales and promotions: A more general model. Manuscript, National University of Singapore.

Klein, L., G. Ford. 2003. Consumer search for information in the digital age: An empirical study of pre-purchase search for automobiles. J. Interactive Marketing 17(3) 29-34.

Kleindorfer, P., D. J. Wu. 2003. Integrating long-term and short-term contracting via business-to-business exchanges for capitalintensive industries. Management Sci. 49(11) 1597-1615.

Lee, H., T. Clark, K. Y. Tam. 1999. Research report. Can EDI benefit adopters? Inform. Systems Res. 10(2) 186-195.

Lin, G., M. Ettl, S. Buckley, S. Bagchi, D. D. Yao. 2000. Extendedenterprise supply-chain management at IBM personal systems group and other divisions. Interfaces 30(1) 7-25.

Massetti, B., R. W. Zmud. 1996. Measuring the extent of EDI usage in complex organizations: Strategies and illustrative examples. MIS Quart. 20(3) 331-346.

Moon, Y. 2000. Autobytel.com. HBS case study (May).

Mukhopadhyay, T., S. Kekre. 2002. Strategic and operational benefits of electronic integration in B2B procurement processes. Management Sci. 48(10) 1301-1313.

Narasimhan, C. 1988. Competitive promotional strategies. J. Bus. $61427-449$
Pandraud, R., G. Laurent, E. Lapersonne. 2005. Repeat purchasing of new automobiles by older consumers: Empirical evidence and interpretations. J. Marketing 69 97-113.

Ratchford, B., M. Lee, D. Talukdar. 2003. The impact of the internet on information search for automobiles. J. Marketing Res. 40(2) 193-209.

Rayport, J. F., A. Bajaj, S. Haithcox, M. Kadyan. 1998. Microsoft car point. Harvard Business School case study (June).

Scott-Morton, F., F. Zettlemeyer, J. Risso. 2001. Internet car retailing. J. Indust. Econom. 49(4) 501-519.

Scott-Morton, F., F. Zettlemeyer, J. Risso. 2006. How the Internet lowers prices: Evidence from matched survey and auto transaction data. J. Marketing Res. 43(2) 168-181.

Scott-Morton, F., F. Zettlemeyer, J. Silva-Risso. 2003. Consumer information and discrimination: Does the Internet affect the pricing of new cars to women and minorities. Quantitative Marketing Econom. 1(1) 65-92.

Straub, D., A. Rai, R. Klein. 2004. Measuring firm performance at the network level: A nomology of the business impact of digital supply networks. J. Management Inform. Systems 21(1) 83-114.

Subramani, M. 2004. How do suppliers benefit from information technology use in supply chain relationships? MIS Quart. 28(1) 45-73.

Tsay, A., N. Agarwal. 2004. Channel conflict and coordination in the e-commerce age. Productions Oper. Management 13(1) 93-110.

Varian, H. 1980. A model of sales. Amer. Econom. Rev. 70(4) 651-659.

Viswanathan, S., J. Kuruzovich, S. Gosain, R. Agarwal. 2007. The role of online infomediaries in price discrimination: Evidence from the auto-retailing sector. J. Marketing. Forthcoming.

Zhu, K. 2004. Information transparency of business-to-business electronic markets: A game-theoretic analysis. Management Sci. 50(5) 670-685. 